\title{
Effect of Upper Extremity Robot-Assisted Exercise on Spasticity in Stroke Patients
}

Kyeong Woo Lee, MD, Sang Beom Kim, MD, Jong Hwa Lee, MD, Sook Joung Lee, MD, Seung Wan Yoo, MD

Department of Physical Medicine and Rehabilitation, Dong-A University College of Medicine \& Busan-Ulsan Regional Cardiocerebrovascular Center, Busan, Korea

\begin{abstract}
Objective To determine the efficacy of a stretching and strengthening exercise program using an upper extremity robot, as compared with a conventional occupational therapy program for upper extremity spasticity in stroke patients.

Methods Subjects were randomly divided into a robot-assisted therapy (RT) group and a conventional rehabilitation therapy (CT) group. RT group patients received RT and CT once daily for 30 minutes each, 5 days a week, for 2 weeks. RT was performed using an upper-extremity robot (Neuro-X; Apsun Inc., Seoul, Korea), and CT was administered by occupational therapists. CT group patients received CT alone twice daily for 30 minutes, 5 days a week, for 2 weeks. Modified Ashworth Scale (MAS) was used to measure the spasticity of upper extremity. Manual muscle tests (MMT), Manual Function Tests (MFT), Brunnstrom stage, and the Korean version of Modified Barthel Index (K-MBI) were used to measure the strength and function of upper extremity. All measurements were obtained before and after 2-week treatment.

Results The RT and CT groups included 22 subjects each. After treatment, both groups showed significantly lower MAS scores and significant improvement in the MMT, MFT, Brunnstrom stage, and K-MBI scores. Treatment effects showed no significant differences between the two groups.

Conclusion RT showed similar treatment benefits on spasticity, as compared to CT. The study results suggested that RT could be a useful method for continuous, repeatable, and relatively accurate range of motion exercise in stroke patients with spasticity.
\end{abstract}

Keywords Stroke, Robot, Spasticity, Upper extremity

\section{INTRODUCTION}

Spasticity is defined as a velocity-dependent increase in tonic stretch reflex, resulting from over-excitation of the stretch reflex due to upper motor neuron lesions [1]. It occurs frequently in patients with post-stroke hemiple-

Received March 17, 2016; Accepted July 1, 2016

Corresponding author: Seung Wan Yoo

Department of Physical Medicine and Rehabilitation, Dong-A University Hospital, 26 Daesingongwon-ro, Seo-gu, Busan 49201, Korea. Tel: +82-51240-5690, Fax: +82-51-254-8511, E-mail: fallilwy@naver.com

ORCID: Kyeong Woo Lee (http://orcid.org/0000-0001-8785-5535); Sang Beom Kim (http://orcid.org/0000-0002-5622-5933); Jong Hwa Lee (http:// orcid.org/0000-0003-2489-358X); Sook Joung Lee (http://orcid.org/0000-0002-6894-445X); Seung Wan Yoo (http://orcid.org/0000-0003-4955-6969).

(c) This is an open-access article distributed under the terms of the Creative Commons Attribution Non-Commercial License (http://creativecommons.org/ licenses/by-nc/4.0) which permits unrestricted noncommercial use, distribution, and reproduction in any medium, provided the original work is properly cited. Copyright (c) 2016 by Korean Academy of Rehabilitation Medicine 
gia. Excessive spasticity reduces patients' range of motion (ROM) to the extent that it obstructs daily living activities and functional improvement, thereby adversely affecting successful rehabilitation.

Various treatment methods are used to control spasticity, such as exercise, drug therapy, electrostimulation, surgery, and local nerve block using botulinum toxin [2-5]. Conventional rehabilitation therapy for spasticity administered by therapists includes passive stretching and ROM exercise treatment. The amount and effects of repetitive exercise manually induced by therapists may differ according to the therapists' levels of experience [6]. In recent decades, rehabilitation treatment using a robot has been developed to reproduce accurate motions repeatedly with less input of physical effort and time by therapists. Upper extremity rehabilitation treatment using robots has been available since the 1990s and the clinical effects on upper extremity function recovery are reported.

Studies on robotic assisted rehabilitation therapy in stroke patients have shown significant improvement in motor abilities of the exercised limb and enhanced functional outcomes [7-11]. However, some studies indicated that when the duration and intensity of conventional treatment is matched with robotic treatment, motor recovery, activities of daily living, strength, and motor control show no group-wise differences [7]. Nevertheless, additional sessions of robotic treatment promote better motor recovery in patients with stroke, as compared with additional conventional treatment [12].

Previously, studies indicated variable treatment effects of robot-assisted rehabilitation treatment on upper extremity spasticity. Fazekas et al. [13] reported significant change in Modified Ashworth Score (MAS) of shoulder adductors and elbow flexor only in the robotic treatment group. However, it reportedly has a small, non-significant effect on muscle tone based on MAS in other studies $[10,11,14]$.

The aim of the present study was to evaluate the effect of upper extremity rehabilitation robots on spasticity in stroke patients. We conducted a randomized controlled trial to evaluate upper extremity spasticity, motor power and functions in response to therapy.

\section{MATERIALS AND METHODS}

\section{Subjects}

The present study included subacute stroke patients with upper extremity spasticity of $\geq 1$ point on the MAS, who were admitted to Department of Rehabilitation Medicine of Dong-A University Hospital from April 2014 to January 2016. Exclusion criteria were non-compliance due to cognitive impairment, medical history of stroke, nervous system disease, or musculoskeletal disease, and medical history of injury to an upper extremity or upper chest area or surgery.

All patients had received general physical, occupational therapies before enrollment in the study. The Institutional Review Board of Dong-A University Hospital approved the study (No. 15-236), and written consent was obtained from all patients.

Enrolled patients were randomly divided into two groups including a robot-assisted rehabilitation therapy (RT) group and a control group that received conventional rehabilitation therapy (CT). The randomization procedure was carried out by an independent person. Enrolled patients were randomly allocated to one of the two groups (RT or CT) in a 1:1 ratio using a computerized table of random numbers.

The RT group performed robot-assisted upper extremity rehabilitation exercises once daily and conventional upper extremity rehabilitation exercises once daily. The CT group performed conventional upper extremity rehabilitation exercises twice daily. Each training protocol was applied over 20 sessions (30 minutes per session, 2 sessions per day, 5 days a week, for 2 weeks).

\section{Robot assisted rehabilitation therapy programs}

The RT exercise was delivered with the upper extremity rehabilitation robot Neuro-X (Apsun Inc., Seoul, Korea) (Fig. 1). Neuro-X robot allows patients to perform shoulder abduction-adduction and elbow flexion-extension movements in the horizontal plane; it is a planar, twodegree-of-freedom robot providing exercises to the upper extremity as the patient's paretic arm moves along $360^{\circ}$ horizontal rotational motion, with an end effector. The design of the robot is based on 2 axis selective compliance assembly robot arm (SCARA) [15]. This device has several treatment modes, including a continuous passive motion exercise (CPM), and controlled assisted move- 
ment exercise (CAM, or active assisted exercise). The robots were controlled with the on-off control algorithm. As participants attempt to move the handle, the robot's sensor detects the movement and measures the strengths (Appendix 1); the robotic assist is turned on when mea-

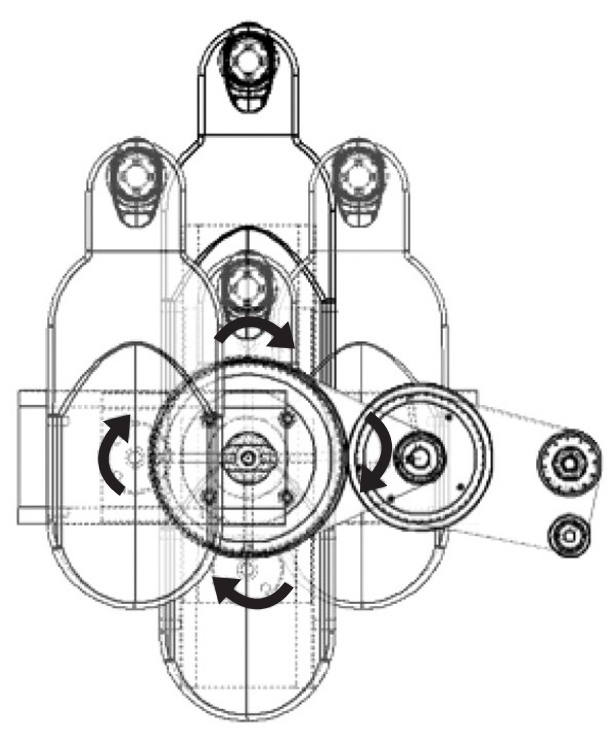

Fig. 1. Schematic of a Neuro-X (Apsun Inc., Seoul, Korea) working method. sured strengths exceed previous setting thresholds. Previous setting thresholds were obtained at the start of each treatment sessions to determine proper exercise intensity. Thresholds were evaluated through isokinetic measurement test in the robot program.

For all robot tasks, the patients were seated on an adjustable chair in front of a monitor. The paretic arm was placed in a customized arm support fixed to the robot end-effector. The therapist monitored the patient's shoulder joint in order to maintain joint position. If needed, patients' trunk was restrained by a harness to decrease compensatory movements.

Two forms of robotic therapy such as continuous passive and active-assisted isokinetic exercise were provided. Subjects performed 10 minutes of continuous passive exercise and 20 minutes of active assisted exercise. Before the active assisted exercise, subjects' motor thresholds were evaluated through isokinetic measurement test in the robot's software program, and subjects subsequently performed the exercise. Several game programs including basic CPM and CAM mode, grinding millstone game, jumping rope game were used in RT exercise (Fig. 2). During this intervention, the robot provided horizontal rotational movement at an angular velocity of $30^{\circ}$ per second, allowing shoulder abduction-adduction and el-
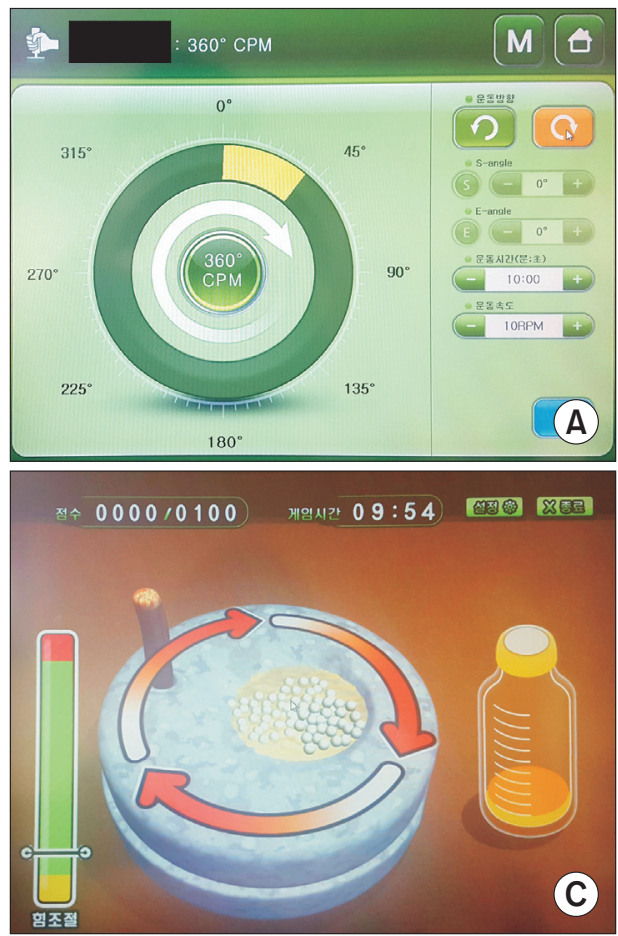

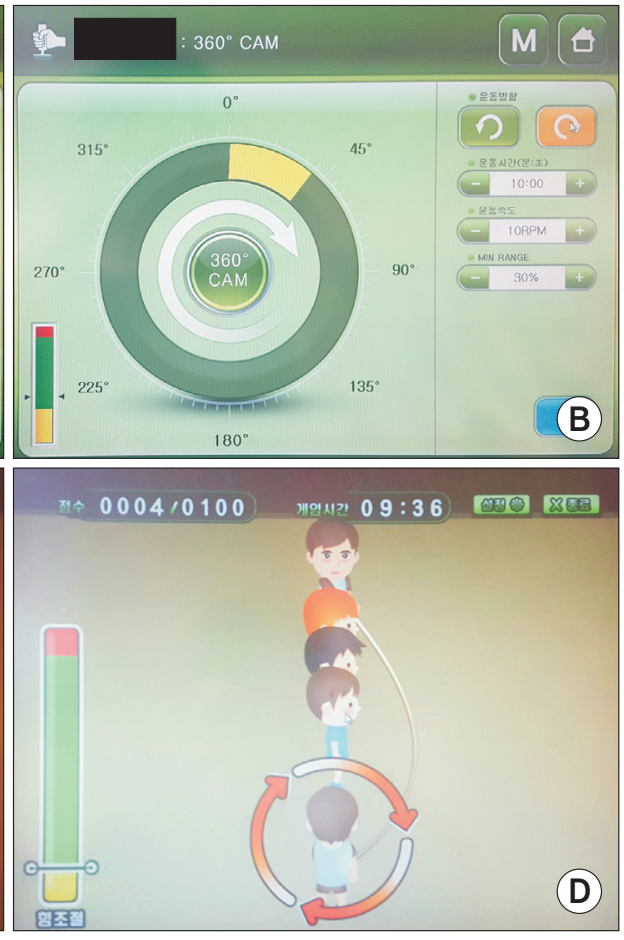

Fig. 2. Four game programs on the Neuro-X system (Apsun Inc., Seoul, Korea). (A) Basic continuous passive motion exercise (CPM) mode. (B) Basic controlled assisted movement exercise (CAM) mode. (C) Grinding millstone. (D) Jumping rope. 
bow flexion-extension. During the training, each subject could carry out ROM and stretching exercise on elbow flexion and extension in the elbow range from $0^{\circ}$ to $120^{\circ}$, with $0^{\circ}$ representing full extension, and $-20^{\circ}$ of horizontal shoulder adduction and $65^{\circ}$ of horizontal shoulder $a b$ duction (Fig. 3).

During RT, patients who performed ROM exercise could get feedback from the monitor, and the upper extremity motor power could be measured to allow resistant exercise. Spastic muscles were stretched and antagonist muscles were contracted in shoulder abductor, adductor and elbow flexor and extensor during the exercises. A bar gauge with a preset target point for the patient is used to monitor the robot. The movement of game program and patient's movement were synchronized, so all ROM exercise could be conducted. Through RT, stiffened upper extremities could be stretched and muscle-strengthening exercises could be induced.

The upper extremity rehabilitation therapy was implemented under the supervision of occupational therapists, who monitored patient's postural movements to limit or prevent postural variation of trunk and/or shoulder, and performed program changes.

\section{Conventional rehabilitation therapy programs}

In the CT group, stretching and strengthening exercises were induced by the occupational therapists, and passive and/or active assistive ROM exercises were implemented based on the patient's motor power and ability.

\section{Evaluation methods}

To examine the degrees of improvement in the two groups, the following tests were administered before and after the 2-week implementation of upper extremity rehabilitation training.

Spasticity was evaluated using the MAS [16] by measuring the elbow flexor and horizontal shoulder adductor. The MAS facilitates passive evaluation of ROM, regardless of speed. When measuring the MAS of horizontal shoulder adduction, patient's shoulder was held in $90^{\circ}$ forward flexion by the examiner. The manual muscle test (MMT) was used to measure muscle strength. Upper extremity motor functions were evaluated using the Manual Function Test (MFT) [17]. This test scores upper extremity exercise, grip strength, and finger manipulation abilities for a possible total of 32 points. Brunnstrom stages show the degree of motor function recovery [18]. K-MBI
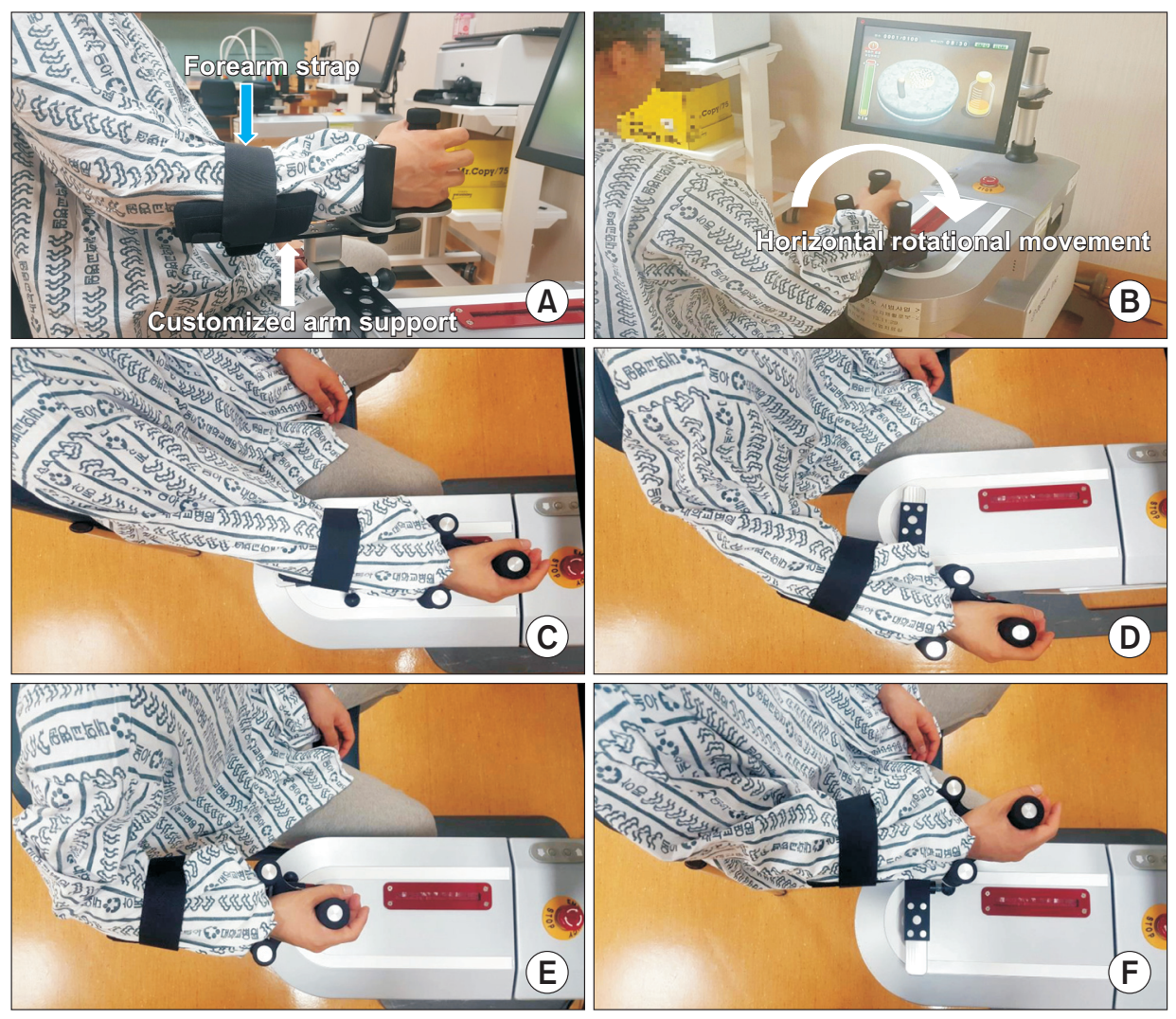

Fig. 3. Neuro-X system, an upper limb rehabilitation robot, consisted of a monitor and upper limb exercise equipment. (A) Paretic arm is placed in a custom-made arm support fixed to the robot. (B) Robot system affording horizontal rotational movement training of upper extremity. (C) Robot system delivering elbow extension. (D) Robot system delivering shoulder abduction. (E) Robot system delivering elbow flexion. (F) Robot system delivering shoulder adduction. 


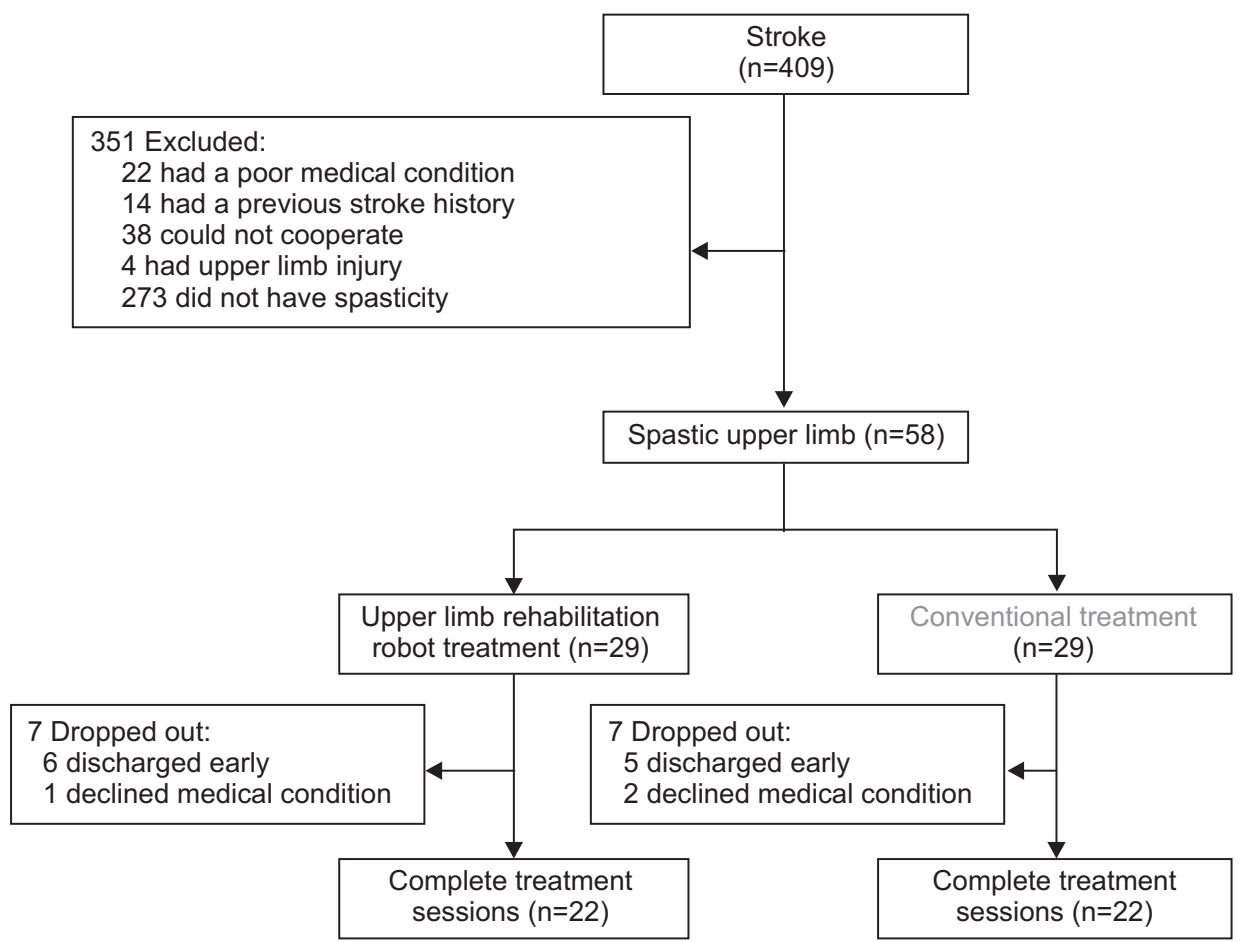

Fig. 4. The algorithm for subject enrollment. was administered to evaluate degree of self-reliance in daily living activities. None of the drugs or performance of procedures that could affect spasticity were changed during the study period.

\section{Statistical analysis}

Statistical analyses were conducted using SPSS ver. 18.0 for Windows (SPSS Inc., Chicago, IL, USA). The Wilcoxon signed-rank test was used to evaluate outcome measurements before and after treatment in each group. For comparison between the two groups, statistical processing was conducted with the Mann-Whitney U-test. A statistical significance level was set at $\mathrm{p}<0.05$.

\section{RESULTS}

During the study period, 409 stroke patients were admitted to our department. Among them, 58 patients showed upper extremity spasticity and were enrolled in the study. Twenty-nine patients each were assigned randomly to the RT or the CT group. Fourteen patients dropped out due to early discharge from the hospital and decline in medical condition. Finally, 44 subjects were included, and completed the study (Fig. 4). Average age of the RT group ( $\mathrm{n}=22$ ) was $50.27 \pm 11.11$ years and CT group $(\mathrm{n}=22)$ was $52.32 \pm 8.66$ years. Basic information was similar between the two groups. MAS, MMT, MFT, Brunnstrom stages, and K-MBI showed no significant differences between the two groups (Table 1).

After the 2-week upper extremity treatment for spasticity, significant improvements were observed in the values of the MAS on elbow flexor and shoulder adductor, the MMT of shoulder abductor, shoulder adductor, elbow flexor, elbow extensor and the MFT, the Brunnstrom stage, the K-MBI in both groups, as compared to before treatment $(\mathrm{p}<0.05)$ (Table 2).

The MAS, MMT, MFT, Brunnstrom stage, and K-MBI scores showed no significant differences in treatment effects of the two groups (Table 3).

During the RT, no other complications related to upper extremity robot, such as increased shoulder or elbow pain, or skin damage occurred.

\section{DISCUSSION}

Spasticity is one of the clinical symptoms of central nervous system disease due to various causes. It can be observed in stroke patients during the neurologic recovery process. Spasticity can accelerate fine motion disability and synkinesis and suppress antagonistic muscles to hinder voluntary motor functions, leading to muscle atrophy, joint contracture, and adverse effect on the ability to 
Table 1. Baseline characteristics

\begin{tabular}{|c|c|c|c|}
\hline & RT (n=22) & CT $(n=22)$ & p-value \\
\hline Age (yr) & $50.27 \pm 11.11$ & $52.32 \pm 8.66$ & 0.706 \\
\hline Sex (male:female) & $15: 7$ & $14: 8$ & \\
\hline \multicolumn{4}{|l|}{ Lesion } \\
\hline Ischemic:hemorrhagic & $13: 9$ & $12: 10$ & \\
\hline Cortical:subcortical & $20: 2$ & $20: 2$ & \\
\hline Paretic side (right:left) & $11: 11$ & $13: 9$ & \\
\hline Days from stroke onset & $40.91 \pm 22.83$ & $41.86 \pm 20.28$ & 0.760 \\
\hline \multicolumn{4}{|l|}{ MAS } \\
\hline Elbow flexor & $1.91 \pm 0.92$ & $2.09 \pm 0.61$ & 0.438 \\
\hline Shoulder adductor & $1.77 \pm 0.81$ & $1.82 \pm 0.73$ & 0.781 \\
\hline \multicolumn{4}{|l|}{ MMT } \\
\hline Shoulder adductor & $2.18 \pm 0.39$ & $1.77 \pm 0.92$ & 0.145 \\
\hline Shoulder abductor & $1.77 \pm 0.92$ & $1.44 \pm 0.82$ & 0.185 \\
\hline Elbow flexor & $1.60 \pm 1.08$ & $1.40 \pm 0.82$ & 0.249 \\
\hline Elbow extensor & $1.60 \pm 1.08$ & $1.40 \pm 0.82$ & 0.249 \\
\hline MFT & $6.77 \pm 4.81$ & $6.32 \pm 4.80$ & 0.990 \\
\hline Brunnstrom stage & $3.14 \pm 1.28$ & $2.91 \pm 1.19$ & 0.663 \\
\hline K-MBI & $43.95 \pm 19.20$ & $45.27 \pm 13.87$ & 0.621 \\
\hline
\end{tabular}

Values are presented as mean \pm standard deviation.

RT, robot assisted therapy; CT, conventional rehabilitation therapy; MAS, Modified Ashworth Scale; MMT, manual muscle test; MFT, Manual Function Test; K-MBI, Korean version of Modified Barthel Index.

Table 2. Changes of measurements after exercise

\begin{tabular}{|c|c|c|c|c|c|c|}
\hline & \multicolumn{2}{|c|}{ RT $(n=22)$} & \multirow{2}{*}{ p-value } & \multicolumn{2}{|c|}{ CT $(n=22)$} & \multirow{2}{*}{ p-value } \\
\hline & Pre & Post & & Pre & Post & \\
\hline \multicolumn{7}{|l|}{ MAS } \\
\hline Elbow flexor & $1.91 \pm 0.92$ & $1.50 \pm 0.74$ & $0.003^{*}$ & $2.09 \pm 0.61$ & $1.86 \pm 0.77$ & $0.025^{*}$ \\
\hline Shoulder adductor & $1.77 \pm 0.82$ & $1.36 \pm 0.49$ & $0.003^{*}$ & $1.82 \pm 0.73$ & $1.64 \pm 0.73$ & $0.046^{*}$ \\
\hline \multicolumn{7}{|l|}{ MMT } \\
\hline Shoulder adductor & $2.18 \pm 0.39$ & $2.45 \pm 0.51$ & $0.014^{*}$ & $1.77 \pm 0.92$ & $1.95 \pm 1.05$ & $0.046^{*}$ \\
\hline Shoulder abductor & $1.77 \pm 0.92$ & $2.05 \pm 1.09$ & $0.014^{*}$ & $1.44 \pm 0.82$ & $1.60 \pm 1.00$ & $0.046^{*}$ \\
\hline Elbow flexor & $1.60 \pm 1.08$ & $1.84 \pm 1.25$ & $0.014^{*}$ & $1.40 \pm 0.82$ & $1.56 \pm 0.96$ & $0.046^{*}$ \\
\hline Elbow extensor & $1.60 \pm 1.08$ & $1.84 \pm 1.25$ & $0.014^{*}$ & $1.40 \pm 0.82$ & $1.56 \pm 0.96$ & $0.046^{*}$ \\
\hline MFT & $6.77 \pm 4.81$ & $8.41 \pm 5.40$ & $0.000^{*}$ & $6.32 \pm 4.80$ & $7.55 \pm 5.26$ & $0.001^{*}$ \\
\hline Brunnstrom stage & $3.14 \pm 1.28$ & $3.55 \pm 1.47$ & $0.003^{*}$ & $2.91 \pm 1.19$ & $3.23 \pm 1.54$ & $0.008^{*}$ \\
\hline K-MBI & $43.95 \pm 19.20$ & $53.91 \pm 18.92$ & $<0.001$ & $45.27 \pm 13.87$ & $54.91 \pm 16.78$ & $<0.001$ \\
\hline
\end{tabular}

Values are presented as mean \pm standard deviation.

RT, robot assisted therapy; CT, conventional rehabilitation therapy; MAS, Modified Ashworth Scale; MMT, manual muscle test; MFT, Manual Function Test; K-MBI, Korean version of Modified Barthel Index.

${ }^{*} \mathrm{p}<0.05$ by Wilcoxon signed-rank test.

perform daily living activities [19]. Treatments for spasticity include physical therapy, drug treatment, surgery such as selective posterior rhizotomy, local nerve block using phenol or botulinum toxin, electro-stimulation, and extracorporeal shock wave therapy. The effects of these therapies differ among patients, have high costs, 
Table 3. Comparison of the exercise effect between two groups

\begin{tabular}{|c|c|c|c|c|}
\hline & RT $(n=22)$ & CT $(n=22)$ & p-value & Adjusted p-value ${ }^{a)}$ \\
\hline \multicolumn{5}{|l|}{$\triangle$ MAS } \\
\hline Elbow flexor & $-0.41 \pm 0.50$ & $-0.23 \pm 0.43$ & 0.201 & 0.898 \\
\hline Shoulder adductor & $-0.36 \pm 0.49$ & $-0.23 \pm 0.43$ & 0.327 & 0.834 \\
\hline \multicolumn{5}{|l|}{$\Delta \mathrm{MMT}$} \\
\hline Shoulder adductor & $0.27 \pm 0.46$ & $0.18 \pm 0.39$ & 0.477 & 0.758 \\
\hline Shoulder abductor & $0.27 \pm 0.46$ & $0.14 \pm 0.35$ & 0.268 & 0.864 \\
\hline Elbow flexor & $0.27 \pm 0.46$ & $0.14 \pm 0.35$ & 0.268 & 0.864 \\
\hline Elbow extensor & $0.27 \pm 0.46$ & $0.18 \pm 0.39$ & 0.477 & 0.758 \\
\hline$\triangle \mathrm{MFT}$ & $1.64 \pm 1.53$ & $1.23 \pm 1.80$ & 0.235 & 0.790 \\
\hline$\Delta$ Brunnstrom stage & $0.41 \pm 0.50$ & $0.32 \pm 0.48$ & 0.536 & 0.729 \\
\hline$\Delta \mathrm{K}-\mathrm{MBI}$ & $9.95 \pm 7.09$ & $9.55 \pm 6.46$ & 0.953 & 0.579 \\
\hline
\end{tabular}

Values are presented as mean \pm standard deviation.

RT, robot assisted therapy; CT, conventional rehabilitation therapy; MAS, Modified Ashworth Scale; MMT, manual muscle test; MFT, Manual Function Test; K-MBI, Korean version of Modified Barthel Index.

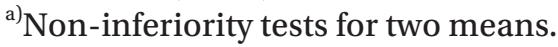

and adverse effects.

Exercise is the basic treatment for spasticity and is implemented first because of ease in application and few adverse effects. Stretching exercise is effective in reducing spasticity because it increases the expansibility of the tissues [6,20-22]. However, conventional exercise treatment might be less efficient or patients might not concentrate on the treatment and have a negative awareness because the same motion is induced for a long time by the therapist [23,24]. Jung et al. [25] and Kim et al. [26], compared upper extremity stretching devices vs. no stretching, among 21 and 15 chronic stroke patients, respectively; in both studies, the group that performed stretching exercises experienced significant spasticity relief.

Several recent studies showed that strength exercise does not increase spasticity or reduce ROM in the affected limbs. Instead, strengthening training increases strength, functional outcomes, and quality of life; and reduces musculoskeletal impairment, without exacerbating spasticity in patients with upper neuron lesion including stroke [27-29].

Some studies have shown that although robot-assisted upper extremity rehabilitation therapy improved motor ability and muscle strength, the performance of daily living activities were not significantly improved [30-33] possibly since previous robot-assisted upper extremity rehabilitation therapy was limited to the proximal part of the upper extremity. To achieve functional improvement, harmony between the proximal part and the distal part is essential $[34,35]$. However, our results showed functional improvement after robot training, possibly due to some degree of hand motion control in our patients.

Game programs included in robotic devices also have positive effects, since they stimulate patients' internal competitive spirits and satisfy their desire for interactions, thereby inspiring their will for treatment. The game programs induce pleasure and interest in the rehabilitation therapy, thus promoting motor learning $[36,37]$. The robot assisted training responses in our study agreed with the reported results on patients' reactions to the game.

Previous studies showed diverse effects of robot-assisted upper extremity rehabilitation therapy on spasticity. Sale et al. [38] and Hesse et al. [39] reported decreases in spasticity and improvements in motor ability; whereas, Masiero et al. [10], Chang et al. [14], and Fasoli et al. [11] reported that spasticity did not significantly decrease despite improvement in upper extremity function and muscle strength.

Robot devices can provide repetitive, highly intensive, task-oriented, enhanced sensory feedback, and mutual treatment. Task-specific and high-intensity exercise in an active and functional manner has shown enhanced motor recovery in stroke patients over a large number of trials [11]. Systematic review of the results suggest that when the duration/intensity of conventional rehabilitative care is matched with that of RT, motor function 
shows no significant difference between the two groups; however, when the RT is used as additional therapy, the motor function recovery in the RT groups is significantly higher than the standard CT groups [12]. These results differed from our findings in motor function. In our study design, rehabilitation program was provided for the same frequency and duration to both the RT and CT groups; and total treatment sessions were the same, without additional robotic intervention.

The MAS and MMT scores of upper extremity before and after the 2-week treatment indicated significant relief of spasticity and motor recovery in both RT and CT groups. Treatment effects showed no significant groupwise difference.

The CT sessions were time-matched with the RT sessions. Rate of movement repetition was not precisely matched to the robot, but overall intensity was greater than that of a conventional exercise program [40]. Thus, robot-assisted exercise might have a greater effect on spasticity than conventional exercise.

In particular, the present study focused on implementing active assistive muscle strengthening exercises together with stretching exercises. It is possible that the action of the patients can have a stretching effect as well as strengthening by active force to induce robotic movement; in addition, it contributes to the positive effect on the treatment process by encouraging active participation and motivation.

However, the present study had limitations in demonstrating functional improvement effects, because of inability to train the hand and insufficient functional evaluation methods. Moreover, the treatment effects were evaluated after a 2-week treatment regimen, which is a relatively short period. In this study, we used outcome measures focused on the shoulder abduction/adduction and elbow flexion/extension movement only, and did not control for other possible movement. Future studies with larger numbers of patients, control group studies, and studies on the effects of long-term continuous treatment for spasticity are necessary.

In conclusion, the RT provided similar spasticity relief as the CT. The RT can induce patients to perform accurate motions repeatedly and motivate them to participate in treatment by arousing interest through games; it can be implemented safely under a therapist's supervision and can lighten therapists' workloads. Our result sug- gested that the RT could be a useful method for continuous, repeatable, and relatively accurate ROM exercise in patients with spasticity.

\section{CONFLICT OF INTEREST}

No potential conflict of interest relevant to this article was reported.

\section{ACKNOWLEDGMENTS}

This study was promoted as part of the spread business of market creation type robots of the Ministry of Trade, Industry and Energy and was carried out by rehabilitation robots supplied from the Ministry of Health \& Welfare and the National Rehabilitation Center in 2013.

\section{REFERENCES}

1. Lance JW. Symposium synopsis. In: Feldman RG, Young RR, Koella WP, editors. Spasticity: disordered motor control. Chicago: Year Book Medical Publishers; 1980. p. 485-94.

2. Kim HW, Ko YJ, Kang SY, Lee JI, Kim IS. The effect of electrical stimulation on spasticity in hemiplegic patients. J Korean Acad Rehabil Med 2000;24:631-6.

3. Odeen I, Knutsson E. Evaluation of the effects of muscle stretch and weight load in patients with spastic paraplegia. Scand J Rehabil Med 1981;13:117-21.

4. Oki A, Oberg W, Siebert B, Plante D, Walker ML, Gooch JL. Selective dorsal rhizotomy in children with spastic hemiparesis. J Neurosurg Pediatr 2010;6:353-8.

5. Gallichio JE. Pharmacologic management of spasticity following stroke. Phys Ther 2004;84:973-81.

6. Selles RW, Li X, Lin F, Chung SG, Roth EJ, Zhang LQ. Feedback-controlled and programmed stretching of the ankle plantarflexors and dorsiflexors in stroke: effects of a 4-week intervention program. Arch Phys Med Rehabil 2005;86:2330-6.

7. Kahn LE, Zygman ML, Rymer WZ, Reinkensmeyer DJ. Robot-assisted reaching exercise promotes arm movement recovery in chronic hemiparetic stroke: a randomized controlled pilot study. J Neuroeng Rehabil 2006;3:12.

8. Lum PS, Burgar CG, Shor PC, Majmundar M, Van der Loos M. Robot-assisted movement training compared 
with conventional therapy techniques for the rehabilitation of upper-limb motor function after stroke. Arch Phys Med Rehabil 2002;83:952-9.

9. Lum PS, Burgar CG, Van der Loos M, Shor PC, Majmundar M, Yap R. MIME robotic device for upperlimb neurorehabilitation in subacute stroke subjects: a follow-up study. J Rehabil Res Dev 2006;43:631-42.

10. Masiero S, Celia A, Rosati G, Armani M. Roboticassisted rehabilitation of the upper limb after acute stroke. Arch Phys Med Rehabil 2007;88:142-9.

11. Fasoli SE, Krebs HI, Stein J, Frontera WR, Hogan N. Effects of robotic therapy on motor impairment and recovery in chronic stroke. Arch Phys Med Rehabil 2003;84:477-82.

12. Norouzi-Gheidari N, Archambault PS, Fung J. Effects of robot-assisted therapy on stroke rehabilitation in upper limbs: systematic review and meta-analysis of the literature. J Rehabil Res Dev 2012;49:479-96.

13. Fazekas G, Horvath M, Troznai T, Toth A. Robotmediated upper limb physiotherapy for patients with spastic hemiparesis: a preliminary study. J Rehabil Med 2007;39:580-2.

14. Chang JJ, Tung WL, Wu WL, Huang MH, Su FC. Effects of robot-aided bilateral force-induced isokinetic arm training combined with conventional rehabilitation on arm motor function in patients with chronic stroke. Arch Phys Med Rehabil 2007;88:1332-8.

15. Krebs HI, Volpe BT, Williams D, Celestino J, Charles SK, Lynch D, et al. Robot-aided neurorehabilitation: a robot for wrist rehabilitation. IEEE Trans Neural Syst Rehabil Eng 2007;15:327-35.

16. Sloan RL, Sinclair E, Thompson J, Taylor S, Pentland B. Inter-rater reliability of the modified Ashworth Scale for spasticity in hemiplegic patients. Int J Rehabil Res 1992;15:158-61.

17. Miyamoto S, Kondo T, Suzukamo Y, Michimata A, Izumi S. Reliability and validity of the Manual Function Test in patients with stroke. Am J Phys Med Rehabil 2009;88:247-55.

18. Brandstater ME. Stroke rehabilitation. In: DeLisa JA, Gans BM, editors. Physical medicine and rehabilitation: principles and practice. 4th ed. Philadelphia: Lippincott Williams \& Wilkins; 2005. p. 1655-76.

19. Katz RT, Rymer WZ. Spastic hypertonia: mechanisms and measurement. Arch Phys Med Rehabil 1989;70:144-55.
20. Nuyens GE, De Weerdt WJ, Spaepen AJ Jr, Kiekens C, Feys HM. Reduction of spastic hypertonia during repeated passive knee movements in stroke patients. Arch Phys Med Rehabil 2002;83:930-5.

21. Harvey LA, Batty J, Crosbie J, Poulter S, Herbert RD. A randomized trial assessing the effects of 4 weeks of daily stretching on ankle mobility in patients with spinal cord injuries. Arch Phys Med Rehabil 2000;81:1340-7.

22. Monaghan K, Horgan F, Blake C, Cornall C, Hickey PP, Lyons BE, et al. Physical treatment interventions for managing spasticity after stroke. Cochrane Database Syst Rev 2011;7:CD009188.

23. Chang YJ, Chen SF, Huang JD. A Kinect-based system for physical rehabilitation: a pilot study for young adults with motor disabilities. Res Dev Disabil 2011;32:2566-70.

24. Yong Joo L, Soon Yin T, Xu D, Thia E, Pei Fen C, Kuah $\mathrm{CW}$, et al. A feasibility study using interactive commercial off-the-shelf computer gaming in upper limb rehabilitation in patients after stroke. J Rehabil Med 2010;42:437-41.

25. Jung YJ, Hong JH, Kwon HG, Song JC, Kim C, Park S, et al. The effect of a stretching device on hand spasticity in chronic hemiparetic stroke patients. NeuroRehabilitation 2011;29:53-9.

26. Kim EH, Chang MC, Seo JP, Jang SH, Song JC, Jo HM. The effect of a hand-stretching device during the management of spasticity in chronic hemiparetic stroke patients. Ann Rehabil Med 2013;37:235-40.

27. Morris SL, Dodd KJ, Morris ME. Outcomes of progressive resistance strength training following stroke: a systematic review. Clin Rehabil 2004;18:27-39.

28. Pak S, Patten C. Strengthening to promote functional recovery poststroke: an evidence-based review. Top Stroke Rehabil 2008;15:177-99.

29. Ada L, Dorsch S, Canning CG. Strengthening interventions increase strength and improve activity after stroke: a systematic review. Aust J Physiother 2006;52:241-8.

30. Mehrholz J, Hädrich A, Platz T, Kugler J, Pohl M. Electromechanical and robot-assisted arm training for improving generic activities of daily living, arm function, and arm muscle strength after stroke. Cochrane Database Syst Rev 2012;6:CD006876.

31. Prange GB, Jannink MJ, Groothuis-Oudshoorn CG, 
Hermens HJ, Ijzerman MJ. Systematic review of the effect of robot-aided therapy on recovery of the hemiparetic arm after stroke. J Rehabil Res Dev 2006;43:17184.

32. Kwakkel G, Kollen BJ, Krebs HI. Effects of robotassisted therapy on upper limb recovery after stroke: a systematic review. Neurorehabil Neural Repair 2008;22:111-21.

33. Lo AC, Guarino PD, Richards LG, Haselkorn JK, Wittenberg GF, Federman DG, et al. Robot-assisted therapy for long-term upper-limb impairment after stroke. N Engl J Med 2010;362:1772-83.

34. Oujamaa L, Relave I, Froger J, Mottet D, Pelissier JY. Rehabilitation of arm function after stroke. Literature review. Ann Phys Rehabil Med 2009;52:269-93.

35. Timmermans AA, Seelen HA, Willmann RD, Kingma H. Technology-assisted training of arm-hand skills in stroke: concepts on reacquisition of motor control and therapist guidelines for rehabilitation technology design. J Neuroeng Rehabil 2009;6:1.

36. Saposnik G, Teasell R, Mamdani M, Hall J, McIlroy W, Cheung D, et al. Effectiveness of virtual reality us- ing Wii gaming technology in stroke rehabilitation: a pilot randomized clinical trial and proof of principle. Stroke 2010;41:1477-84.

37. Edmans J, Gladman J, Hilton D, Walker M, Sunderland A, Cobb S, et al. Clinical evaluation of a non-immersive virtual environment in stroke rehabilitation. Clin Rehabil 2009;23:106-16.

38. Sale P, Mazzoleni S, Lombardi V, Galafate D, Massimiani MP, Posteraro F, et al. Recovery of hand function with robot-assisted therapy in acute stroke patients: a randomized-controlled trial. Int J Rehabil Res 2014;37:236-42.

39. Hesse S, Schulte-Tigges G, Konrad M, Bardeleben A, Werner C. Robot-assisted arm trainer for the passive and active practice of bilateral forearm and wrist movements in hemiparetic subjects. Arch Phys Med Rehabil 2003;84:915-20.

40. Conroy SS, Whitall J, Dipietro L, Jones-Lush LM, Zhan M, Finley MA, et al. Effect of gravity on robot-assisted motor training after chronic stroke: a randomized trial. Arch Phys Med Rehabil 2011;92:1754-61. 
Appendix 1. Sensor specification

\begin{tabular}{|ll}
\hline \multicolumn{1}{|c}{ Specification } & \multicolumn{1}{c|}{ Accuracy } \\
\hline Rated capacity (RC) & $10-50,000 \mathrm{kgf} / \mathrm{cm}$ \\
\hline Rated output (RO) & $1.5 \mathrm{mV} / \mathrm{V}$ \\
\hline Non-linearity & $\leq 0.3 \% \mathrm{RO}$ \\
\hline Hysteresis & $\leq 0.3 \% \mathrm{RO}$ \\
\hline Non-repeatability & $\leq 0.3 \% \mathrm{RO}$ \\
\hline Terminal resistance, input & $350 \Omega \pm 1 \%$ \\
\hline Terminal resistance, output & $350 \Omega \pm 1 \%$ \\
\hline Insulation resistance & $2,000 \mathrm{M} \Omega$ \\
\hline Temperature effect on rated output & $\leq 0.1 \% \mathrm{Load} / 10^{\circ} \mathrm{C}$ \\
\hline Temperature effect on zero balance & $\leq 0.1 \% \mathrm{RO} / 10^{\circ} \mathrm{C}$ \\
\hline Excitation voltage & $10 \mathrm{~V} \mathrm{DC}$ \\
\hline Safe overload & $150 \% \mathrm{RC}$ \\
\hline Cable & $\varphi 7 \mathrm{shield} 5 \mathrm{~m}$ \\
\hline
\end{tabular}

